\title{
Regime Shifts in the Behaviour of International Currency and Equity Markets: A Markov-Switching Analysis
}

\author{
Pami Dua ${ }^{1} \cdot$ Divya Tuteja $^{2}$
}

Accepted: 27 October 2021 / Published online: 10 December 2021

(c) The Author(s), under exclusive licence to The Indian Econometric Society 2021

\begin{abstract}
This paper examines regime switching behaviour and dynamic linkages among currency and equity markets of Eurozone, India, Japan and U.S. using a Markovswitching framework. First, we seek to characterize the market specific and common regime shifts in international stock and currency markets. Second, we aim to study regime-dependent conditional correlations across these markets. We estimate state-dependent models for the financial markets in a univariate Markov-switching Autoregression (MS-AR) as well as a multivariate Markov-switching Vector Autoregression (MS-VAR) framework. The paper utilizes weekly data from July, 1999 to October, 2020 to model the interactions among the markets. Our univariate results identify two-states viz. bull state (bear state) characterized by high returns (low returns) and low volatility (high volatility) for the stock market indices and Euro/ USD and INR/USD returns. For the Yen/USD market the bull state corresponds to depreciation accompanied by low volatility. Further, we employ a multivariate formulation to study the regimes across asset classes which provides additional insights into the common states across the markets. Using the MS-VAR model encompassing stocks and currencies, we find a tranquil regime characterized by lower volatility and higher returns and a turbulent regime depicted by higher volatility and lower returns. Contemporaneous correlations among asset market pairs are sharper during the crises. Some of the turbulent periods highlighted in the analysis include the dot-com bubble burst, South American crisis, 9/11, Iraq war, housing bubble burst, global financial crisis, Eurozone debt crisis, Taper Tantrum, Brexit, U.S. Federal Government Shutdown, U.S.-China Trade War and the recent COVID-19 pandemic.
\end{abstract}

Keywords Stock markets $\cdot$ Exchange rates $\cdot$ Markov-switching $\cdot$ Regimes $\cdot$ Linkages

Pami Dua

dua@econdse.org

Divya Tuteja

divya@iift.edu

1 Department of Economics, Delhi School of Economics, University of Delhi, New Delhi, India

2 Economics Division, Indian Institute of Foreign Trade, New Delhi, India 
JEL Classification C34 $\cdot$ E44 · G15

\section{Introduction}

It is well established in the literature that optimal allocation of assets in the portfolio of international investors entails accounting for co-movements across asset markets. This necessitates modelling of the joint distribution of asset returns, especially in the context of regime switching (Guidolin and Timmermann 2007). Moreover, with an acceleration in the process of financial globalization, we expect market regimes across asset classes and countries to overlap. This is especially true during times of turbulence in international markets such as the U.S. financial crisis of 2008-09 and the Eurozone Sovereign Debt crisis of 2010-12. In particular, recent evidence (Chan et al. 2011) suggests that during the global financial crisis, linkages across various asset classes were reinforced. Identifying the overlap of turmoil time periods in the markets has significant implications for portfolio diversification strategies. Additionally, it can enable the policy makers to calibrate interventions which may help avert a 'contagion' like situation in the equity markets or currency crises.

Theoretical contribution by international macro-finance studies such as Pavlova and Rigobon (2008) suggests that stock and foreign exchange markets may be more inter-linked during certain times (of high volatility) than others (with low volatility). Pavlova and Rigobon (2008), in particular, construct a theoretical Center-Periphery model with portfolio constraints to explain the phenomena of contagion across stock markets and exchange rates during the East Asian crisis of 1997-98. They show that portfolio constraints generate wealth transfers between the Periphery and Center economies, which increase the co-movement of stock prices across the Periphery countries and is associated with the phenomenon of 'contagion'.

Some of the empirical work that investigates the possibility of contagion across equity and currency markets includes Granger et al. (2000), Boschi (2005), Kallberg et al. (2005), Kanas (2005), Flavin et al. (2008), Dungey and Martin (2007), Tai (2007), Walid et al. (2011), and Dua and Tuteja (2016). In a recent study Dua and Tuteja (2016) show that holding a portfolio across stock and currency markets may be beneficial from the perspective of diversification as it is likely to be subject to lower risks in view of the negative correlation between most equity and foreign exchange returns during recent crises.

The seminal papers by Hamilton $(1989,1990)$ highlight the Markov-switching framework for characterizing regime shifts in economic time series such as business cycles. Markov-switching models introduce a hidden or 'unobservable' state variable which follows a Markov chain process to represent the multiple regimes. These non-linear models are characterised by model parameters being a function of states generated by a Markov chain process. The regime switching model, henceforth, is more insightful since it segregates the data generating process of asset market returns into 'bear' and 'bull' market phases.

A handful of studies investigate the relationship between exchange rate returns and stock returns utilizing the Markov-switching framework such as Kanas (2005), Chkili et al. (2011) and Chkili and Nguyen (2014). The empirical literature 
investigating the relationship between international stock and currency markets has primarily utilized the Vector Autoregressive/Vector Error Correction and GARCH methodology (or single-regime models). We, instead, attempt to study the dynamic linkages and co-movement among currency and equity markets in a regime-switching framework. This paper examines the regime switching behaviour of international financial markets viz. Eurozone, India, Japan, and U.S. equity markets and currency markets using the Markov switching autoregressive (MS-AR) and vector autoregressive (MS-VAR) models. We seek to characterize the market specific as well as common regime shifts in international stock and currency markets.

The present study contributes to the existing literature in the following aspects. First, extant studies examining regimes in stock markets and exchange rates using the Markov-switching framework are scarce (Kanas 2005; Chkili et al. 2011; Chkili and Nguyen 2014) and we add to this strand of the literature. Second, in contrast to the existing studies which tend to focus on linkages across currency and equity markets within a country, we focus on market-specific as well as common regimes (i.e. for the stock markets and currency markets individually and also across stock and currency markets internationally). Third, other studies investigating this issue cited above which utilize the Markov-switching framework have dealt with only emerging markets. To the best of our knowledge, this is the first study which focuses on a sample of developed and emerging country markets. Further, this is supported by the theory developed by Pavlova and Rigobon (2008) which suggests that contagion spreads from the Center i.e. developed markets to the Periphery i.e. emerging economies. Finally, we employ weekly data for the period July, 1999 to October, 2020, which includes the dot-com bubble curst of 2001-02, the global financial crisis of 2008-09, the Eurozone crisis of 2010-2013 and most recent COVID-19 pandemic.

The rest of the paper is organized as follows: "Empirical Studies Using Markov Switching Framework to Study Financial Markets" presents the empirical literature utilizing the Markov-switching framework to study financial markets, especially foreign exchange and stock markets. The subsequent, "Methodology, Estimation Strategy and Data", discusses the methodology, estimation strategy and data utilized in the paper. Next, the results of our study would form "Results". The last section spells out the conclusions.

\section{Empirical Studies Using Markov Switching Framework to Study Financial Markets}

In this section, we highlight the following strands of the literature. First, papers that deal with the inter-linkages between stock and exchange rate returns in the Markovswitching framework. Second, other studies that model the financial market returns using a Markov-switching framework.

The empirical literature investigating the causality between international stock and currency markets has primarily utilized the Vector Autoregressive/Vector 
Error Correction and GARCH methodology ${ }^{1}$ (or single-regime models). A handful of studies investigate the relationship between exchange rate returns and stock returns utilizing the Markov-switching framework ${ }^{2}$ such as Kanas (2005), Chkili et al. (2011) and Chkili and Nguyen (2014). Kanas (2005) investigates the volatility regime linkages between the currency market of Mexico and stock markets of Mexico, Brazil, Argentina, Hong Kong, Hungary and Thailand. The paper finds high-volatility regime dependence amongst the Mexican currency and the stock markets. Chkili et al. (2011) utilize a Markov-switching EGARCH model to study the linkages between stock price volatility and changes in exchange rate of Hong Kong, Malaysia, Mexico and Singapore during the period 1994-2009. The analysis identifies two regimes characterized by low returns-high variance and high returnslow variance. Further, the relationship between stock and currency markets is found to be regime-dependent. Chkili and Nguyen (2014) utilize a Markov switching Vector Autoregressive (VAR) model to study the interactions between stock returns and exchange rate returns for Brazil, Russia, India, China and South Africa (BRICS) and find that the impact of the stock markets on the exchange rates is higher across the states.

We also present a brief discussion of the other studies that have utilized the Markov-switching framework to model asset market returns. The paper by Guidolin and Timmermann (2006) has instigated research on nonlinear dynamics of various asset classes using Markov switching models. Chesnay and Jondeau (2001) employ MS-VAR to study the relationship between S\&P 500, DAX and FTSE. Tillmann (2004) studies interest rate spreads, yield on Brady Bonds and yield on 10-year US Treasury bills in a Markov switching framework. Dueker and Neely (2007) utilize the Markov switching specification to study the relationship among exchange rates viz. German Mark, Euro, Yen, Pound and Swiss Franc. Chang (2009) analyses S\&P 500, dividend yield, default premium and interest rate in a Markov switching setup. Chan et al. (2011) study an array of assets US stocks, Treasury bonds, Oil, Gold and US Case Shiller Index. Qiao et al. (2011) also examine the inter-linkages among ASX, NZ and S\&P 500 stock markets in such a framework. Chevallier (2012) explores a wide range of asset prices and economic time series in a Markov switching specification which includes US Current Account Balance, Loans secured by Real Estate, Home Mortgage Liabilities of Households, TED Spread, US Residential Property Prices, US Industrial Production Gold price, Oil prices and S\&P 500.

\footnotetext{
1 The studies that investigate the relationship between stock market and exchange rates include Granger et al. (2000), Hatemi-J. and Roca (2005), Phylaktis and Ravazzolo (2005), Pan et al. (2007), Zhao (2010), Diamandis and Drakos (2011), Lin (2012), Andreou et al. (2013) and Tsagkanos and Siriopoulos (2013) among others.

2 Some of the papers that utilize the Markov-switching framework to model interactions across multiple assets are Guidolin and Timmermann (2006), Chang (2009), Chan et al. (2011), Guo et al. (2011) and Chevallier (2012) and Bae et al. (2014). A few recent studies have utilized the Markov-switching framework to analyse the impact of factors such as uncertainty, risk and gold as a hedge for the equity and currency markets. These include Roubaud and Arouri (2018), Zolfaghari and Sahabi (2017) and Chkili (2017).
} 
Based on a study of the existing literature, we find that the present study differs from the existing literature on the regime-switching behaviour of currency and stock markets. The present study contributes to the existing literature in the following aspects. The existing studies which tend to focus on linkages across currency and equity markets within a country, we focus on market-specific as well as common regimes (i.e. for the stock markets and currency markets individually and also across stock and currency markets internationally). The existing studies investigating this issue cited above which utilize the Markov-switching framework have dealt with only emerging markets. Further, this is supported by the theory developed by Pavlova and Rigobon (2008) which suggests that contagion spreads from the Center i.e. developed markets to the Periphery i.e. emerging economies. Finally, we employ weekly data for the period July, 1999 to October, 2020, which includes the dot-com bubble curst of 2001-02, the global financial crisis of 2008-09, the Eurozone crisis of 2010-2013 and most recent COVID-19 pandemic.

\section{Methodology, Estimation Strategy and Data}

This section discusses the methodological aspects of Markov-switching models along with the empirical estimation strategy adopted and the data utilized in the present study.

\section{Methodology: MS-AR and MS-VAR Models}

In this sub-section, we describe the univariate and multivariate Markov-switching models that are employed in our analysis. To begin with, we set up univariate Markov-switching Autoregression (MS-AR) models for each of the asset markets separately which enable us to capture the non-linearities and switching behaviour exhibited by the individual markets along with identification of market-specific regimes. This is followed by an analysis of common regimes across asset-classes i.e. in the currency markets and stock markets using the multivariate Markov-switching Vector Autoregression (MS-VAR) model.

The phenomena of regime-switching in economic time series can be captured in two alternative frameworks-Observation switching and Markov-switching. The former assumes that the switching probabilities are a function of the lagged observed variables or the observed variables have a feedback effect on the switching variable. However, the regime change itself is regarded as an unobserved stochastic or random event in the case of Markov switching model (Hamilton 1994). The simplest probabilistic law or specification that governs a transition from state 1 to state 2 is obtained by assuming that $S_{t}$ which is a discrete-valued random variable capturing the state of the world to be the realization of a Markov chain. It has been noted in Krolzig (1997) that the deterministic regime switching models are special cases of a Markov-switching vector autoregressive model. 
In accordance with Hamilton (1989, 1990) and Guidolin (2011), the switching behaviour of a univariate time series can be described by a two-state first-order Markov switching autoregressive (MS-AR with lags $m$ ) model, ${ }^{3}$

$$
y_{t}=\mu_{S_{t}}+\sum_{l=1}^{m} \phi_{S_{t} l} y_{t-l}+\sigma_{S_{t}} \varepsilon_{t}
$$

where $y_{t}$ denotes the stock market/exchange returns of Eurozone, India, Japan and U.S., $\mu_{S_{t}}=\mu_{1}, \mu_{2}$ is the regime-dependent intercept in states one and two respectively; $\phi_{S_{t}}=\phi_{1 l}, \phi_{2 l}$ are the regime-dependent autoregressive coefficients in states one and two respectively; $m$ denotes the optimal AR lag order; and $\sigma_{S_{t}}^{2}=\sigma_{1}^{2}, \sigma_{2}^{2}$ is the regime-dependent variance ${ }^{4}$ in states one and two respectively. Further, $S_{t}=1,2$ is the random variable governing the switching process in the model ${ }^{5}$ and is the realization of a two-state Markov chain process. The time-varying volatility for the markets is calculated in accordance with Wang and Theobald (2008). ${ }^{6}$

We represent the first and second moments of returns in the Eurozone, Indian, Japanese, and U.S. stock markets and exchange rates by a seven-dimensional multivariate Markov switching model with heteroscedasticity. This specification has been chosen since it allows us to characterize the dynamic (lagged) linkages (captured by the Vector Autoregressive $\operatorname{VAR}(p)$ model) along with the contemporaneous conditional correlations or co-movements between asset returns (which we derive from the non-diagonal variance-covariance matrix $\Sigma_{S_{t}}$ ) across regimes in a single framework.

We utilize the Markov Switching Intercept Autoregressive Heteroscedasticity (MSIAH) model discussed in Guidolin (2011) which has the following general form for a two-regime MS-VAR $(m)$ process

$$
y_{t}=\mu_{S_{t}}+\sum_{l=1}^{m} \beta_{S_{t}} y_{t-l}+\varepsilon_{t}
$$

\footnotetext{
${ }^{3}$ It is noteworthy that this is a special case of the multivariate model (presented later) with $y_{t}$ denoting a single time series or asset market.

${ }^{4} \sigma_{S_{t}}=\sigma_{1}, \sigma_{2}$ denote the corresponding regime-dependent standard deviation in states one and two respectively.

${ }^{5}$ The Expectation-Maximization (EM) algorithm (Dempster et al., 1977) is employed to estimate the Markov-switching models.

${ }^{6}$ Wang and Theobald (2008) have proposed constructing the time-varying market volatility for each of the markets based on the full information set by using the smoothed probabilities and the parameter estimates under.

$$
E\left[\tilde{\sigma}_{t}^{2} \mid \mathcal{F}_{T}\right]=\tilde{\sigma}_{1}^{2} E\left[S_{t}=1 \mid \mathcal{F}_{T}\right]+\tilde{\sigma}_{2}^{2} E\left[S_{t}=2 \mid \mathcal{F}_{T}\right],
$$

where $\tilde{\sigma}_{1}^{2}$ and $\tilde{\sigma}_{2}^{2}$ are the estimated conditional variances for regimes one and two respectively and $\mathcal{F}_{T}$ is the full information set upto time $T$.
} 
where $y_{t}=\left[\begin{array}{c}s^{E Z} \\ s^{I N D} \\ s^{J P N} \\ s^{U S} \\ e^{E Z} \\ e^{I N D} \\ e^{J P N}\end{array}\right]$ is the $7 \times 1$ vector of endogenous variables i.e. returns on the

Eurozone $\left(s^{E Z}\right)$ stock market, returns on the Indian $\left(s^{I N D}\right)$ stock market, returns on the Japanese $\left(s^{J P N}\right)$ stock market, returns on the U.S. $\left(s^{U S}\right)$ stock market, returns on the Euro/Dollar $\left(e^{E Z}\right)$ exchange rate, returns on the Rupee/Dollar $\left(e^{I N D}\right)$ exchange rate and returns on the Yen/Dollar $\left(e^{J P N}\right)$ exchange rate; $\mu_{S_{t}}$ is a $7 \times 1$ vector of regime-dependent mean returns; $\beta_{S_{l} l}$ is the $7 \times 7$ matrix of regime-dependent VAR coefficients and $S_{t}=1,2$ (and in general we assume the number of regimes to be $k$ ) is a latent state variable driving all the parameter matrices and is a two-state ${ }^{7}$ Markov chain process with the transition matrix

$$
\begin{gathered}
\mathbb{P}=\left[\begin{array}{ll}
p_{11} & p_{12} \\
p_{21} & p_{22}
\end{array}\right] \\
P\left\{S_{t}=j \mid S_{t-1}=i, S_{t-2}=h, \ldots, y_{t-1}, y_{t-2}, \ldots\right\}=P\left\{S_{t}=j \mid S_{t-1}=i\right\}=p_{i j}
\end{gathered}
$$

This process characterizes a two-state Markov chain with transition probabilities ${ }^{8}$ $\left\{p_{i j}\right\}_{i, j=1,2}$. The residuals follow a standard Gaussian distribution conditional on the state i.e. $\varepsilon_{t} \sim N\left(0, \Sigma_{S_{t}}\right)$. The $7 \times 7$ matrix $\Sigma_{S_{t}}$ represents the state factor $\left(S_{t}\right)$ in a regime-dependent variance-covariance matrix such that

$$
\Sigma_{S_{t}}=\left[\begin{array}{ccc}
\sigma_{1,1, S_{t}} & \ldots & \sigma_{1,7, S_{t}} \\
\cdot & \cdots & \cdot \\
\cdot & \cdots & \cdot \\
\cdot & \cdots & \cdot \\
\sigma_{7,1, S_{t}} & \cdots & \sigma_{7,7, S_{t}}
\end{array}\right]
$$

The contemporaneous correlation between the asset returns in two markets $p$ and $q$ in regime $S_{t}$ will be given by

$$
\rho_{p, q, S_{t}}=\frac{\sigma_{p, q, S_{t}}}{\sigma_{p, p, S_{t}} \sigma_{q, q, S_{t}}} .
$$

\footnotetext{
${ }^{7}$ The two-state framework is a simplification since there may actually exist more than two states. This is particularly true of multivariate models where the total number of states increase at an exponential rate. We are grateful to the anonymous Reviewer for pointing this out.

${ }^{8}$ The transition probabilities are obtained by conditioning on the information available in the previous period whereas we obtain the smoothed probability by conditioning on the full information set.
} 
When $k=1$, then the model reduces to a standard single-regime VAR process. The other variants of the process are MSI, and MSIA which indicate the absence of regime-switching in autoregressive (A) parameters and heteroscedasticity $(\mathrm{H})$ respectively.

\section{Estimation Strategy}

In this sub-section, we elucidate the estimation strategy that we adopt in the paper. The first step of the econometric methodology is to test if the variables used in the analysis are nonstationary or contain a unit root. While a plethora of unit root tests exist in the literature, in this paper, we adopt the Dickey-Fuller generalized least squares (DF-GLS) test proposed by Elliot et al. (1996) and the Lee and Strazicich (2003) minimum LM test for a unit root which allows for structural breaks in the null hypothesis of a unit root (and we assume two breaks). Thereafter, we test for nonlinearity in the time series by utilizing Tsay's test (Tsay 1986).

We, then, select the lag order of the linear Autoregressive (V) AR model. The AR orders are selected on the basis of the Box-Jenkins methodology (Krolzig 1997). This is accomplished by inspecting the autocorrelation function-partial autocorrelation function plots and, subsequently, estimating the ARMA specifications. These are then compared using Akaike Information Criterion (AIC), Bayesian Information Criterion (BIC) along with the Portmanteau Q-statistic for autocorrelation in the residuals. Standard lag selection and lag exclusion tests (AIC, BIC, Hannan Quinn HQ and LR test statistics) are employed to select the lag order of the VAR model.

Subsequently, we test for the presence of Markov switching in the asset market returns. In order to test for the Markov switching in asset returns, we conduct two tests. To ascertain if the linear AR/ VAR model is inadequate, the corrected likelihood ratio (LR) test proposed by Davies (1977) along with the modified LR $\left(L R^{\text {Wolfe }}\right)$ test for a mixture of normal proposed by Wolfe (1971) have been utilized to test for the presence of multiple regimes. ${ }^{9}$

\footnotetext{
${ }^{9}$ Both the tests account for the problem of identification of the nuisance parameters under the null hypothesis. Hansen (1992) and Garcia (1993) have discussed the asymptotic distribution of the LR statistic being dependent on the data at hand and the parameters, and that testing for the number of regimes is a problematic issue since the states are "disappearing" and so are the elements corresponding to these in the probability transition matrix. Therefore, the parameters under the null hypothesis can practically take any value without affecting the underlying likelihood function and are, hence, termed as "nuisance parameters". Davies (1977) has derived an upper bound for the level of significance of the LR statistic in the presence of these nuisance parameters and is given by.
}

$$
P(L R>x) \leq P\left(\chi_{1}^{2}>x\right)+\sqrt{2 x} \exp \left(-\frac{x}{2}\right)\left[\Gamma\left(\frac{1}{2}\right)\right]^{-1},
$$

where $\Gamma($.$) is the standard gamma function. The modified LR statistic for multiple regimes utilised by$ Turner and Startz (1989) and proposed by Wolfe (1971) is given by:

$$
L R^{\text {Wolfe }}=-\frac{2}{T}(T-3)\left[L L(\tilde{\theta})-L L\left(\tilde{\theta}_{r}\right)\right] \rightarrow^{d} \chi_{r}^{2}
$$

where $L L\left(\tilde{\theta}_{r}\right)$ is the log-likelihood of the model under the null hypothesis of a single-regime model, $T$ is the sample size, and $r=n(n-1)$ as there are $n(n-1)$ parameters which cannot be estimated under the null of no regime switching. 
There are several ways to select the best Markov-switching model specification (such as formal testing based on the likelihood ratio and use of information criterion). We compare the alternative Markov switching specifications on the basis of the maximum value of $A I C_{k}$ and $B I C_{k}$ criteria to determine the best specification for the markets. ${ }^{10}$ These are defined as: $A I C_{k}=L L_{k}-n_{k}$ and $B I C_{k}=L L_{k}-\frac{1}{2} \log (T) n_{k}$, where $L L_{k}$ is the maximum log-likelihood when a model with $k$ states is estimated, $T$ is the sample size and $n_{k}$ is the total number of parameters in the model (Wang and Puterman 1999).

Finally, a regime classification measure (RCM) proposed by Ang and Bekaert (2002) for the appropriateness of the Markov-switching specification is also reported. ${ }^{11}$ The residuals are tested for remaining autocorrelation using the test given by Goodwin (1993).

\section{Data}

In order to fulfil the objectives of this paper, data at weekly frequency for the stock markets are collected from the Wall Street Journal database and that for the exchange rates are obtained from the website of the Federal Reserve Bank of St. Louis. The sample under study is from July, 1999 to October, 2020. We utilize time series data for the stock and currency markets in Eurozone, India, Japan, and U.S. viz. Stoxx Euro 50 Index $\left(s^{E Z}\right)$, Euro/USD exchange rate $\left(e^{E Z}\right)$, Nikkei Index $\left(s^{J P N}\right)$, Yen/ USD exchange rate $\left(e^{J P N}\right)$, Nifty 50 Index $\left(s^{I N D}\right)$, Rupee/ USD exchange rate $\left(e^{I N D}\right)$ and $\mathrm{S} \& \mathrm{P} 500$ Index $\left(s^{U S}\right)$ (we have defined the exchange rates of Eurozone, India and Japan with respect to that of the U.S.). We study the advanced economies of Eurozone, Japan and U.S. which constituted more than 50\% of the total GDP of OECD economies in 2020 (data.oecd.org, 2020) $^{12}$. In accordance with the theoretical

\footnotetext{
${ }^{10}$ Modified AIC and BIC have been used by several studies utilizing Markov mixture-models such as Sclove (1983) and Wang and Puterman (1999). Under certain conditions, Leroux (1992) has proved that selection of the number of components in a mixture model based on information criterion (AIC or BIC) does not underestimate the number of true components, asymptotically. We, therefore, rely on these criteria to choose the most parsimonious model.

${ }^{11} \mathrm{RCM}$ indicates the adequacy of a $\$ \mathbf{k} \$ \$$-regime model as it is based on the intuition that a good regime-switching model should discriminate between the states clearly so the smoothed probabilities would be either close to zero or one. The RCM statistic for a model with two regimes is defined as.
}

$$
R C M=400 \times \frac{1}{T} \sum_{t=1}^{T} \operatorname{Pr}\left[S_{t}=j \mid \mathcal{F}_{t}\right]\left(1-\operatorname{Pr}\left[S_{t}=j \mid \mathcal{F}_{t}\right]\right),
$$

where the constant term of 400 is used to normalize the statistic between 0 and $100, \operatorname{Pr}\left[S_{t}=j \mid \mathcal{F}_{t}\right]$ is the smoothed probability conditioned on the availability of the full information set $\mathcal{F}_{t}$. In this case, a value of 0 will be assigned to a two-regime model which perfectly distinguishes the states and has a perfect fit and a value of 100 will be assigned to a model which assigns a 0.5 probability of occurrence to both the states, has a poor fit and is inadequate. The literature often uses a standard benchmark of 50 for the RCM statistic.

12 The reason for choosing India vis-à-vis China as the emerging economy in the analysis is that the Indian Rupee has been following a dirty floating exchange rate regime during the study period. This is in contrast to China whose currency has been mostly managed and leaves little scope for analysis. Further, among the Emerging economies, India precedes China as one of the largest and fastest growing in the last decade or so. 
analysis of financial markets and the existing empirical literature, the series for stock market prices (indices) and exchange rates (per USD) are modelled as logarithmic first differences or in returns form.

Table 1 (Panels A and B) presents the descriptive statistics and the unconditional correlation matrix for the returns in the seven markets. The average weekly returns are highest for Nifty 50 and lowest for the Stoxx 50. Further, the most volatile series is also Nifty 50 and the least volatile series is the returns on the INR/USD. The unconditional correlation among the stock markets is generally high and positive. The unconditional correlation across the exchange rate returns is positive and relatively lower except the INR/USD and Yen/USD exchange rates which are negatively correlated. However, the unconditional correlation between the stock markets and the exchange rates is mixed (positive as well as negative).

\section{Results}

We now present and discuss the results and findings of the analyses undertaken to study the regime switching behaviour of the financial markets.

As mentioned before, the endogenous variables have been specified in returns form (log first differences for both the stock and currency markets). Therefore, we conduct the unit root tests for the variables in this form only. The results of the unit root tests are given in Table 2 Panels A (DF-GLS) and B (Lee-Strazicich 2003) and indicate that all the variables are stationary. The results of Tsay's test for non-linearity are given in Table 3 and conclusively imply presence of non-linearities in the series. Using the Box-Jenkins procedure the autoregressive order for all the markets is found to be one (except NIKKEI which gives lag of two) ${ }^{13}$. Lag one is selected for the VAR model using the standard model selection procedure i.e. by utilizing the AIC, BIC and HQ statistics ${ }^{14}$.

\section{Market-Specific Regimes}

To begin with, we must ascertain whether the seven markets individually exhibit regime-switching behaviour or conduct a univariate analysis of the markets. We, therefore, model the conditional marginal distribution of the asset returns separately and fit two-regime MSI/MSIH/MSIA and MSIAH models ${ }^{15}$. We, subsequently, report the modified Akaike information criterion $\left(A I C_{k}\right)$ and modified Bayesian information criterion $\left(B I C_{k}\right)$ statistics which enable us to determine the best Markov switching model specification for each of the markets respectively ${ }^{16}$.

\footnotetext{
13 Results are available with the authors on request.

14 All the model selection criteria suggest lag one as the optimal lag with the maximum lag considered as 8 .

15 We utilize the criterion suggested by Krolzig (1997) to deduce the number of regimes. This is criterion is based on the optimal ARMA or VAR order of the model.

16 Detailed results on $A I C_{k}$ and $B I C_{k}$ statistics are available with the authors on request.
} 
The $A I C_{k}$ and $B I C_{k}$ statistics unanimously select the two-state MSIH model to be the best model as shown by the highest $A I C_{k}$ and $B I C_{k}$ statistics for the all the stock markets as well as the Euro/USD and Yen/USD returns. In case of the Yen/ USD returns, we again choose the MSIH specification even though the $A I C_{k}$ criterion suggests the MSIAH model. This is because $B I C_{k}$ imposes higher penalty on addition of parameters and chooses a more parsimonious specification ${ }^{17}$. Further, it is noteworthy that the MSIH specification is, in general, more parsimonious than the MSIAH specification. This is because the latter allows for state dependent autoregressive coefficients and estimates a larger number of parameters. For the INR/USD returns, the MSI specification is chosen. This specification is even more parsimonious than the MSIH specification.

Table 4 reports the empirical estimation results of the two-state MSIH model for each of the asset markets (except INR/USD which follows MSI model). The null of a single regime is rejected at $1 \%$ level of significance for each of the markets by the LR tests. Note that the mean returns are negative in the first regime and positive in the second regime for all the stock markets and the Yen/USD exchange rate (although insignificant for the latter). Interestingly, the volatility in the negativereturns state is higher for the stock markets and Yen/USD returns. Therefore, the regimes with negative returns and high volatility capture the bear-market and those with positive returns and low volatility coincide with the 'bull' market phases in the markets. However, in the case of the Euro/USD and INR/USD returns, appreciation (or negative returns) is coupled with lower volatility and would indicate a 'bull' regime in the markets. This is possible since depreciation and higher volatility in these markets coincides with periods of turmoil in the global markets. The Yen/ USD behaves differently from the other two currencies possibly due to the Yen carry trade. Other studies like Guidolin and Timmermann (2006) and Chan et al. (2011) also find evidence of state-dependent behaviour in the case of financial markets and specifically show that the two-state model is the best model for stock market returns.

The transition probabilities $p_{11}$ and $p_{22}$ from Table 4 are 0.9579 (bear-regime) and 0.9818 (bull-regime) for Stoxx Index, 0.8805 (bear-regime) and 0.9414 (bullregime) for Nikkei Index, 0.9694 (bear-regime) and 0.9893 (bull-regime) for Nifty 50 Index, 0.9505 (bear-regime) and 0.9729 (bull-regime) for S\&P 500 Index, 0.9813 (bear-regime) and 0.9883 (bull-regime) for Euro/USD rate, 0.9546 (bear-regime) and 0.9968 (bull-regime) for INR/USD rate, and 0.9364 (bear-regime) and 0.9723 (bull-regime) for Yen/USD rate. This indicates that the bull-regime tends to be more persistent $^{18}$ and longer than the bear-regime for all the markets. Further, the bull regime for Euro/USD and INR/USD rates exhibits appreciation. This result in the case of the Eurozone and Indian currencies may be attributed to the inflow of capital into the economies in response to bullish markets (Grangeret al. 2000).

\footnotetext{
17 Peel et al. (2001) show that AIC and BIC are useful bounds for the number of components in a mixture but find that BIC is more accurate as it is correct in six out of eight simulated cases. McLachlan and Peel (2000) discuss several other studies which show that the AIC tends to overestimate the number of components in a mixture. Therefore, in this case we adopt the model suggested by the BIC.

18 The persistence of each regime depends on the transition probabilities. A higher transition probability indicates a higher persistence of that particular regime.
} 
Table 1 Descriptive Statistics

\begin{tabular}{|c|c|c|c|c|c|c|c|}
\hline & $s^{E Z}$ & $s^{I N D}$ & $s^{J P N}$ & $s^{U S}$ & $e^{E Z}$ & $e^{I N D}$ & $e^{J P N}$ \\
\hline \multicolumn{8}{|c|}{ Panel A: Summary statistics } \\
\hline Mean & -0.0002 & 0.0021 & 0.0002 & 0.0008 & -0.0001 & 0.0005 & -0.0001 \\
\hline Std. Dev & 0.0228 & 0.0278 & 0.0257 & 0.0200 & 0.0110 & 0.0076 & 0.0109 \\
\hline Skewness & -0.9912 & -0.5619 & -0.7319 & -1.1690 & 0.0119 & 0.0657 & -0.1197 \\
\hline Kurtosis & 9.5173 & 7.0257 & 6.9970 & 10.0899 & 4.6167 & 8.4329 & 4.4763 \\
\hline Maximum & 0.1076 & 0.1637 & 0.1061 & 0.0831 & 0.0438 & 0.0411 & 0.0481 \\
\hline Minimum & -0.1847 & -0.1481 & -0.1778 & -0.1525 & -0.0658 & -0.0433 & -0.0480 \\
\hline \multicolumn{8}{|c|}{$\begin{array}{l}\text { Panel B: Uncon- } \\
\text { ditional correla- } \\
\text { tions }\end{array}$} \\
\hline$s^{E Z}$ & 1 & & & & & & \\
\hline$s^{I N D}$ & $0.51 * * *$ & 1 & & & & & \\
\hline$s^{J P N}$ & $0.68 * * *$ & $0.51 * * *$ & 1 & & & & \\
\hline$s^{U S}$ & $0.83 * * *$ & $0.49 * * *$ & $0.65^{* * *}$ & 1 & & & \\
\hline$e^{E Z}$ & $0.04 * * *$ & $-0.20 * * *$ & $-0.07 * * *$ & $-0.16^{* * *}$ & 1 & & \\
\hline$e^{I N D}$ & $-0.31 * * *$ & $-0.47 * * *$ & $-0.28 * * *$ & $-0.34 * * *$ & $0.30 * * *$ & 1 & \\
\hline$e^{J P N}$ & $0.30 * * *$ & $0.14 * * *$ & $0.40 * * *$ & $0.20 * * *$ & $0.25 * * *$ & $-0.01 * * *$ & 1 \\
\hline
\end{tabular}

Note: $* * *$ and $* * *$ indicate significance at $10 \%, 5 \%$ and $1 \%$ respectively. $s^{E Z}, s^{I N D}, s^{J P N}, s^{U S}, e^{E Z}, e^{I N D}$ and $e^{J P N}$ denote the returns on Eurozone stock market, Indian stock market, Japanese stock market, U.S. stock market, Euro vs. USD exchange rate, INR vs. USD exchange rate and Yen vs. USD exchange rate respectively

The Euro/USD exchange rate remained particularly strong vis-à-vis USD despite the on-going Eurozone debt crisis. The two exchange rates, therefore, display a bullregime with appreciation of the exchange rate being accompanied by low-volatility and the corresponding bear-regime is associated with depreciation and higher volatility. The regimes in the Eurozone and Indian currency market are counter-cyclical to the stock markets as higher returns or bullish financial markets would lead to inflow of capital and, henceforth, an appreciation of the currency. This is contrary to the pro-cyclical behaviour displayed by safe-haven currencies such as the Yen. Additionally, studies such as Ranaldo and Söderlind (2010) and Dimitriou and Kenourgios (2013) find that Yen is a safe haven currency and, therefore, it appreciates against USD in periods when the stock prices are falling. The RCM statistic is well below 50 for each of the model specifications and the fit is, therefore, good. The test for serial correlation (Goodwin, 1993) indicates that there is no remaining autocorrelation in the residuals.

Figures $1 \mathrm{~A}-\mathrm{G}$ depict the smoothed (ex-post) probability of being in a bear regime for each of the markets. From Fig. $1 \mathrm{~A}-\mathrm{G}$, we gather that the stock markets are broadly in agreement, in terms of identifying the periods of economic turmoil (Regime one). The time-varying volatility estimates based on Wang and Theobald (2008) are also presented for the markets with the exception of INR/ USD. All these markets are affected by four distinct phases-the dot-com bubble burst of 2001-02, the global financial meltdown of 2008-09, the Eurozone 
Table 2 Unit root test results

\begin{tabular}{|c|c|c|c|}
\hline \multicolumn{2}{|l|}{ Variable } & DF-GLS statistic & Inference \\
\hline \multicolumn{4}{|c|}{ Panel A: DF-GLS test (constant and trend) } \\
\hline$s^{E Z}$ & \multicolumn{2}{|c|}{$-6.68 * * *$} & $\mathrm{I}(0)$ \\
\hline$s^{I N D}$ & \multicolumn{2}{|c|}{$-7.12 * * *$} & $\mathrm{I}(0)$ \\
\hline$s^{J P N}$ & \multicolumn{2}{|c|}{$-15.31 * * *$} & $\mathrm{I}(0)$ \\
\hline$s^{U S}$ & \multicolumn{2}{|c|}{$-8.03 * * *$} & $\mathrm{I}(0)$ \\
\hline$e^{E Z}$ & \multicolumn{2}{|c|}{$-14.38 * * *$} & $\mathrm{I}(0)$ \\
\hline$e^{I N D}$ & \multicolumn{2}{|c|}{$-25.00 * * *$} & $\mathrm{I}(0)$ \\
\hline$e^{J P N}$ & \multicolumn{2}{|c|}{$-8.09 * * *$} & $\mathrm{I}(0)$ \\
\hline \multicolumn{4}{|l|}{ Critical values } \\
\hline $10 \%$ & \multicolumn{2}{|c|}{-2.57} & \\
\hline $5 \%$ & \multicolumn{2}{|c|}{-2.89} & \\
\hline $1 \%$ & \multicolumn{2}{|c|}{-3.48} & \\
\hline Variable & Trend break model & Crash model & Inference \\
\hline \multicolumn{4}{|c|}{ Panel B: Lee-Strazicich Unit root test with structural change } \\
\hline$s^{E Z}$ & $-29.20 * * *$ & $-18.09 * * *$ & $\mathrm{I}(0)$ \\
\hline$s^{I N D}$ & $-27.49 * * *$ & $-23.41 * * *$ & $\mathrm{I}(0)$ \\
\hline$s^{J P N}$ & $-28.47 * * *$ & $-27.02 * * *$ & $\mathrm{I}(0)$ \\
\hline$s^{U S}$ & $-28.56 * * *$ & $-21.62 * * *$ & $\mathrm{I}(0)$ \\
\hline$e^{E Z Z}$ & $-26.28 * * *$ & $-26.20 * * *$ & $\mathrm{I}(0)$ \\
\hline$e^{I N D}$ & $-25.49 * * *$ & $-24.38 * * *$ & $\mathrm{I}(0)$ \\
\hline$e^{J P N}$ & $-26.78 * * *$ & $-25.05 * * *$ & $\mathrm{I}(0)$ \\
\hline \multicolumn{4}{|l|}{ Critical values } \\
\hline Crash model & $1 \%$ & $5 \%$ & $10 \%$ \\
\hline$L M_{\tau}$ & -4.545 & -3.842 & -3.504 \\
\hline Trend Break Model & $\lambda_{2}$ & & \\
\hline$\lambda_{1}$ & 0.4 & 0.6 & 0.8 \\
\hline 0.2 & $-6.16,-5.59,-5.27$ & $-6.41,-5.74,-5.32$ & $-6.33,-5.71,-5.33$ \\
\hline 0.4 & - & $-6.45,-5.67,-5.31$ & $-6.42,-5.65,-5.32$ \\
\hline 0.6 & - & - & $-6.32,-5.73,-5.32$ \\
\hline
\end{tabular}

Note: $*, * *$ and $* * *$ indicate significance at $10 \%, 5 \%$ and $1 \%$ respectively. Critical values are at the $1 \%$, $5 \%$ and $10 \%$ levels, respectively. $\lambda_{j}$ denotes the location of breaks. $s^{E Z}, s^{I N D}, s^{J P N}, s^{U S}, e^{E Z}, e^{I N D}$ and $e^{J P N}$ denote the returns on Eurozone stock market, Indian stock market, Japanese stock market, U.S. stock market, Euro vs. USD exchange rate, INR vs. USD exchange rate and Yen vs. USD exchange rate respectively

debt crisis of 2011-12 and the ongoing COVID-19 pandemic. In the case of the currency markets, we find similar episodes being highlighted. The INR/USD exchange rate (Fig. 1F) presents very sharp and short phases of turmoil, possibly due to the proactive intervention on the part of the Reserve Bank of India. It is interesting to note that the bear regime in the Euro/USD exchange rate (Fig. 1E) conforms to the three common periods identified by the individual stock markets' 
Table 3 Test for non-linearity

\begin{tabular}{lll}
\hline Variable & F-test for Non-linearity (Tsay) & Conclusion \\
\hline$s^{E Z}$ & $8.74 * * *$ & Non-linear \\
$s^{I N D}$ & $2.37 * * *$ & Non-linear \\
$s^{J P N}$ & $3.22 * * *$ & Non-linear \\
$s^{U S}$ & $5.36 * * *$ & Non-linear \\
$e^{E Z}$ & $3.08 * * *$ & Non-linear \\
$e^{I N D}$ & $4.15 * * *$ & Non-linear \\
$e^{J P N}$ & $2.82 * * *$ & Non-linear \\
\hline
\end{tabular}

Note: $*, * *$ and $* * *$ indicate significance at $10 \%, 5 \%$ and $1 \%$ respectively. $s^{E Z}, s^{I N D}, s^{J P N}, s^{U S}, e^{E Z}, e^{I N D}$ and $e^{J P N}$ denote the returns on Eurozone stock market, Indian stock market, Japanese stock market, U.S. stock market, Euro vs. USD exchange rate, INR vs. USD exchange rate and Yen vs. USD exchange rate respectively. Since, the data utilized is at weekly frequency, 4 lags are included in the regression

bear regime. The bear regime in the Yen/USD (Fig. 1G) rate seems to identify the same episodes as the stock markets

Therefore, our univariate results identify two-states for all the markets which we inferred to be the bear regime (state one) and the bull regime (state two). The volatility is lower for all the asset markets during the bullish regime as compared to the bearish regime. The bull regime is also found to be more persistent for all the markets except the Euro/USD and the INR/USD exchange rates. In the bullish phase, mean returns of all the markets are higher (barring Euro/USD and INR/USD exchange rates which undergo appreciation) than in the bearish regime. However, since the regime switches are random, we cannot predict these and, therefore, leverage these results for portfolio diversification. Moreover, we observe a high degree of overlap among the regimes and identify three distinct periods of economic contractions (or bear regime) from the analysis viz. the dot-com bubble burst of 2001-02, the global financial meltdown of 2008-09, the Eurozone debt crisis of 2011-12 and the ongoing COVID-19 pandemic of 2020.

\section{Common Regimes}

We now model the conditional joint distribution of the asset returns in the markets. To begin with we determine the best multivariate model for the markets. ${ }^{19} \mathrm{We}$ analyse the model encompassing stock markets as well as currency markets. Further, the most appropriate MS-VAR specification is found to be MSIH $(2,1)$ for the model which includes all the markets. This seems to be plausible since we find MSIH to be the most parsimonious specification for the marginal distributions of the asset returns in all the seven markets.

\footnotetext{
$\overline{19}$ Detailed results for the $A I C_{k}$ and $B I C_{k}$ statistics of the MS-VAR model are available from the authors on request.
} 


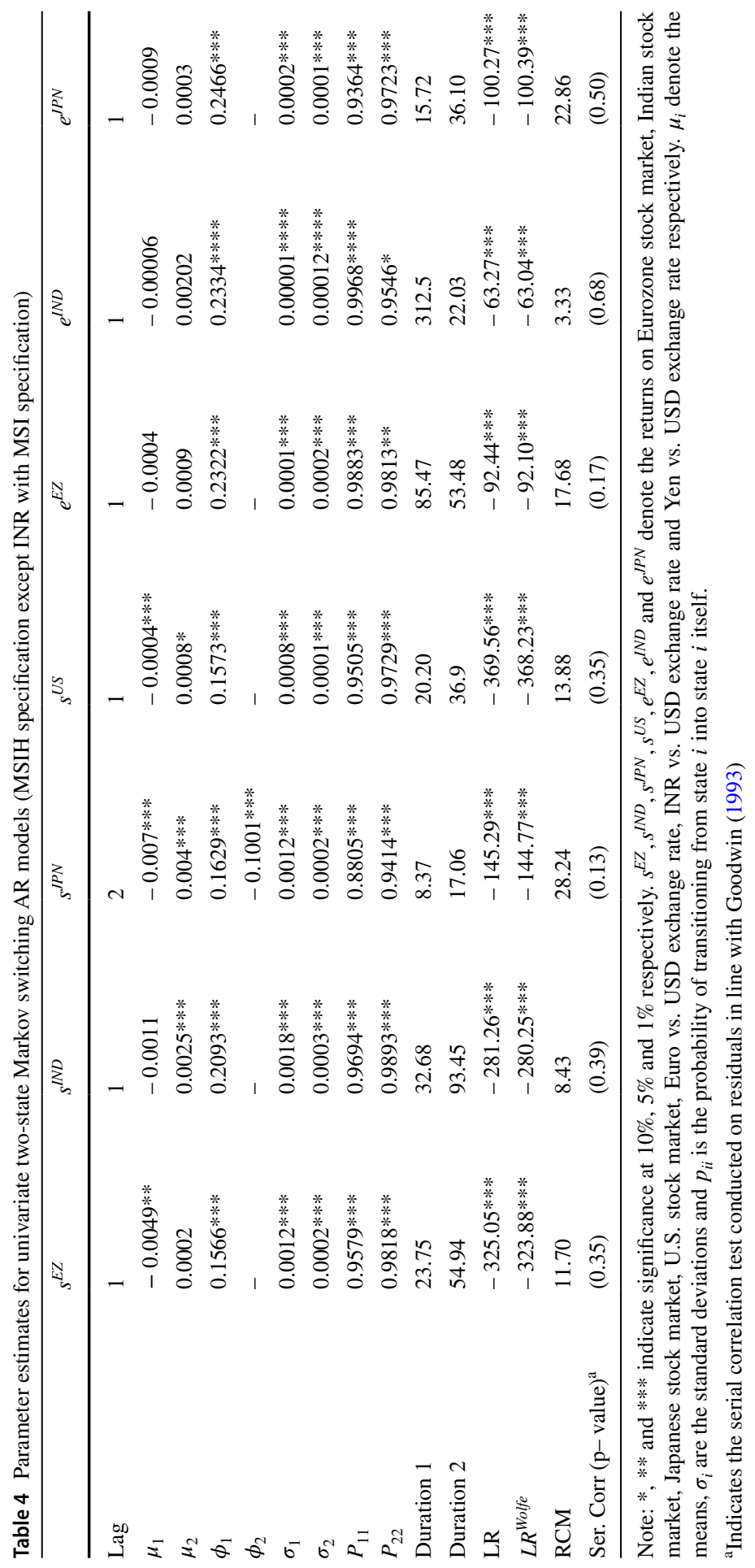




\section{A Stoxx 50 Index}

\section{Smoothed Probability of Bear Regime and Time-varying Volatility}

1.2
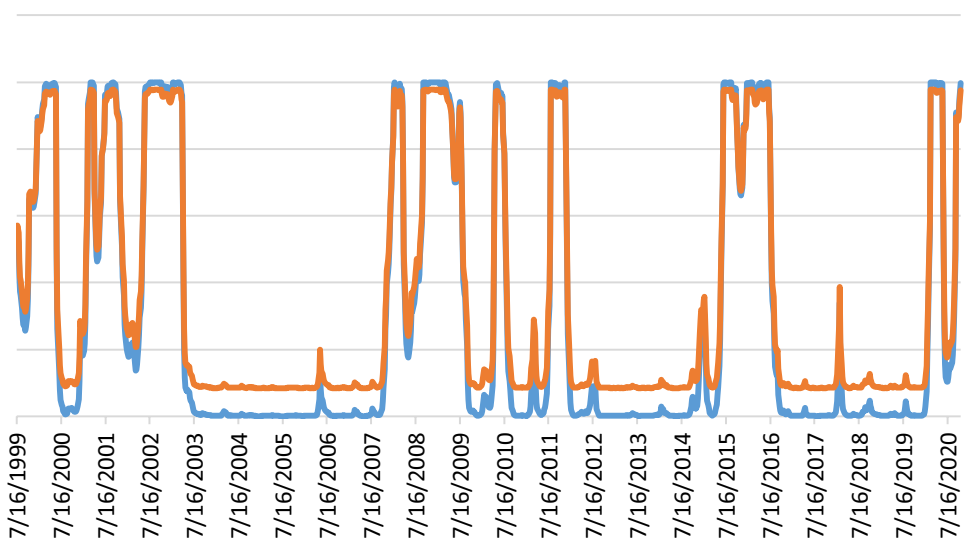

0.0000019

0.0000017

0.0000015

0.0000013

0.0000011

$9 \mathrm{E}-07$

$7 \mathrm{E}-07$

$5 \mathrm{E}-07$

$3 \mathrm{E}-07$

$1 \mathrm{E}-07$

$-1 \mathrm{E}-07$

Smoothed Probability of Bear Regime (LHS)

Time-varying Volatility (RHS)

\section{B Nifty 50 Index}

\section{Smoothed Probability of Bear Regime and Time-varying Volatility}

1.2

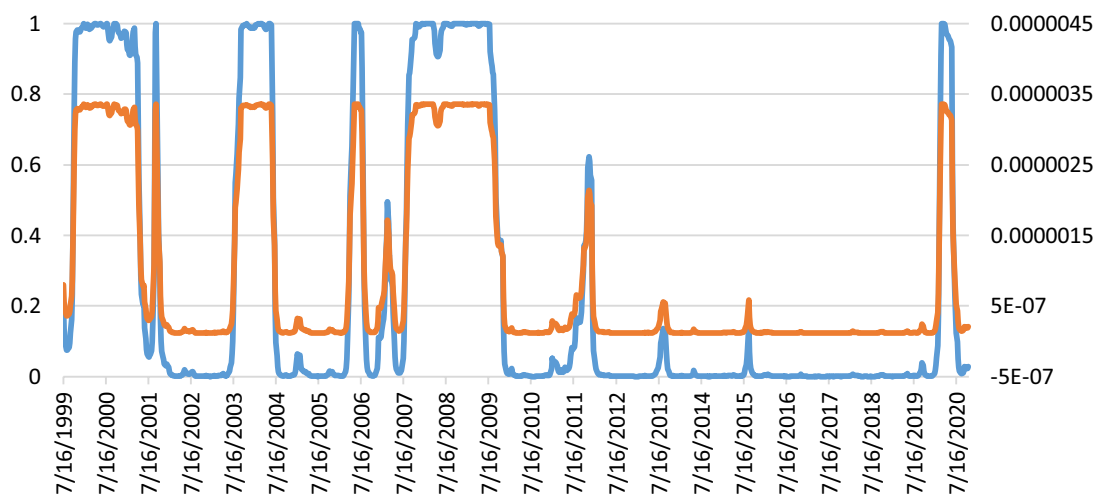

Smoothed Probability of Bear Regime (LHS)

Time-varying Volatility (RHS)

Fig. 1 Smoothed Probability of Bear Regime for univariate Markov Switching models 


\section{S\&P 500 Index}

\section{Smoothed Probability of Bear Regime and Time-varying Volatility}

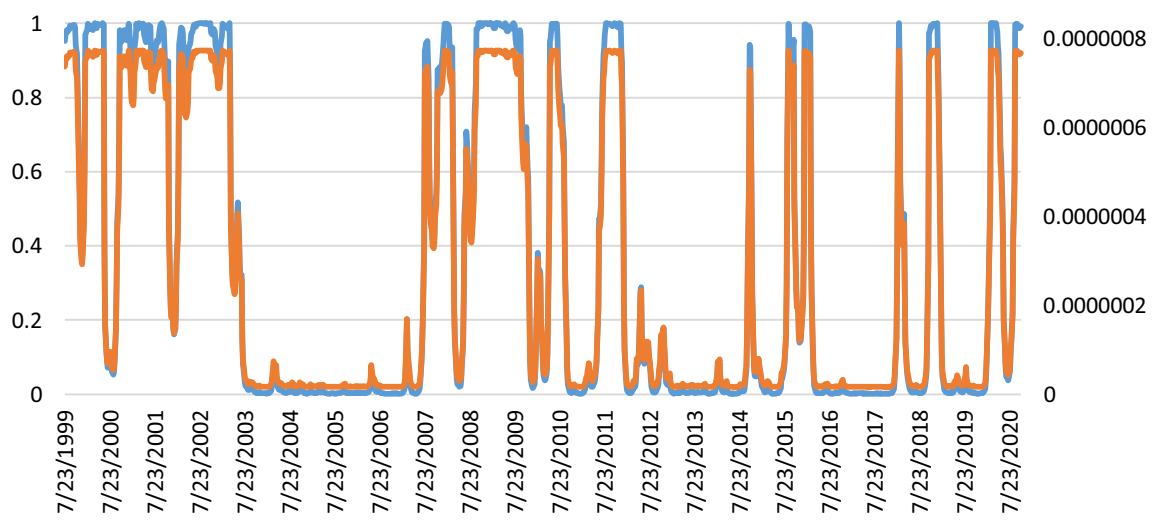

Smoothed Probability of Bear Regime (LHS) —Time-varying Volatility (RHS)

\section{Nikkei Index}

\section{Smoothed Probability of Bear Regime and Time- varying Volatility}

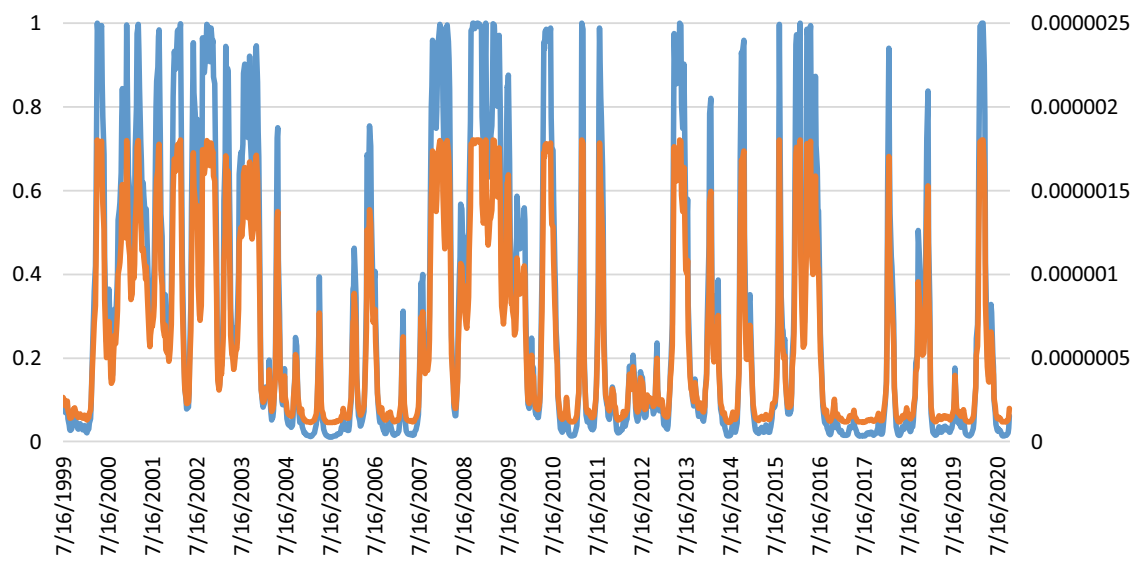

Smoothed Probability of Bear Regime (LHS) T Time-varying Volatility (RHS)

Fig. 1 (continued) 


\section{E Euro/USD Exchange rate \\ Smoothed Probability of Bear Regime and Time-varying Volatility}

1.2 $5 \mathrm{E}-08$

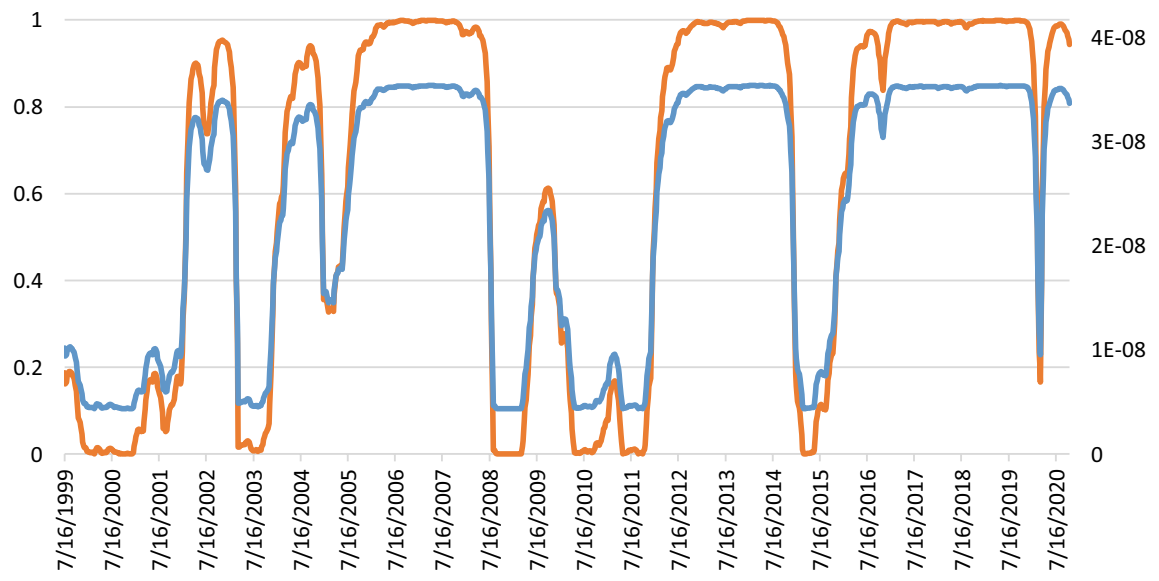

Smoothed Probability of Bear Regime (LHS) _ Time-varying Volatility (RHS)

\section{F INR/USD Exchange rate}

\section{Smoothed Probability of Bear Regime}

1.2

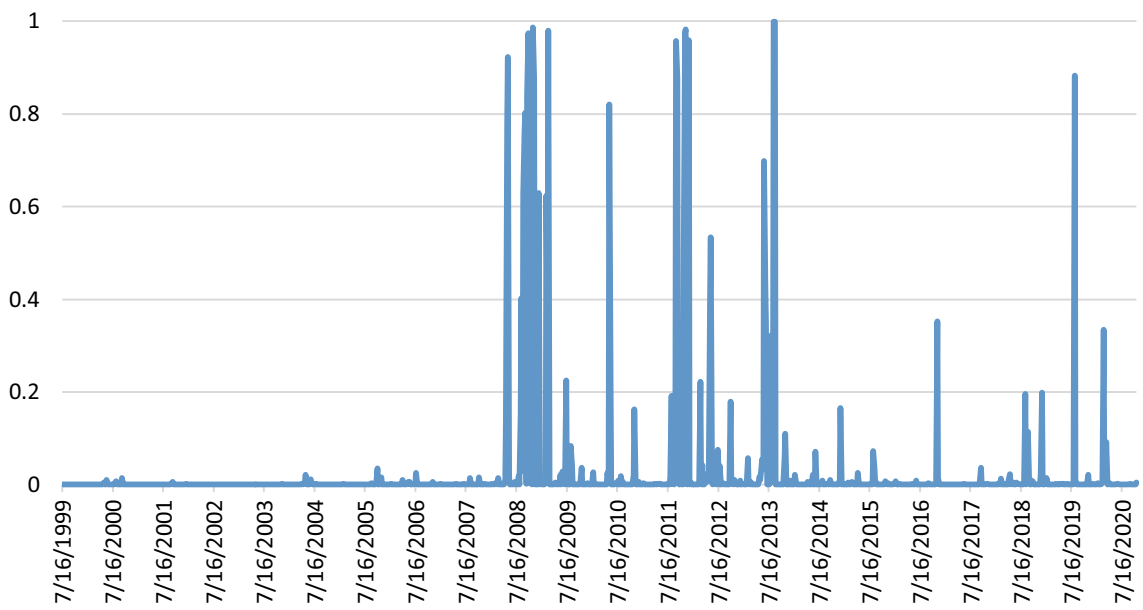

Fig. 1 (continued) 


\section{G Yen/USD Exchange rate}

\section{Smoothed Probability of Bear Regime and Time-varying Volatility}

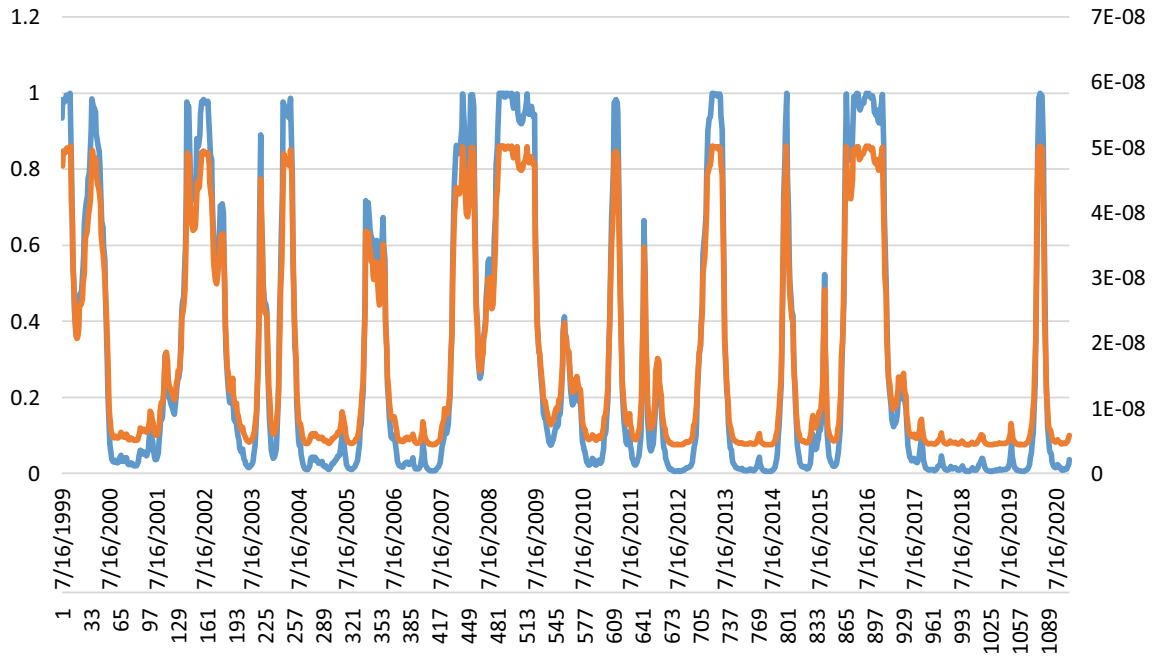

Smoothed Probability of Bear Regime (LHS) —Time-varying Volatility (RHS)

Fig. 1 (continued)

\section{Stock and Currency Markets}

In Table 5 Panel A, parameter estimates of the multivariate MSIH model for the conditional joint distribution of the seven asset market returns are presented. The null hypothesis of a single regime for the model with all the stock and currency markets is rejected at $1 \%$ level of significance by the LR tests. We identify two regimes'tranquil' period which coincides with economic expansions and 'turmoil' period synonymous with economic recessions (Chanet al. 2011). In regime one, the conditional means across all the asset markets are negative except the Euro/USD and the INR/USD rates. This finding is consistent with the univariate model results and with the behaviour of asset prices during a turmoil period i.e. due to higher risk and uncertainty in the stock markets, investors would prefer to invest in safe-haven assets and this leads to a pull out or outflow from stock markets and a depreciation of the exchange rate. The reverse case is true for regime two, which is the case of economic expansion or tranquil market regimes. This would cause the stock markets to attract foreign financial flows, leading to an appreciation of the domestic currency which is the Euro and INR. The results for the Yen are not in conformity with the other two currencies since it is a safe haven currency.

Further, it is clear that the behaviour of stock markets during both the regimes is synchronized in the sense that a fall in returns happens simultaneously across all the stock markets. This is evident from negative returns during the turbulent state 


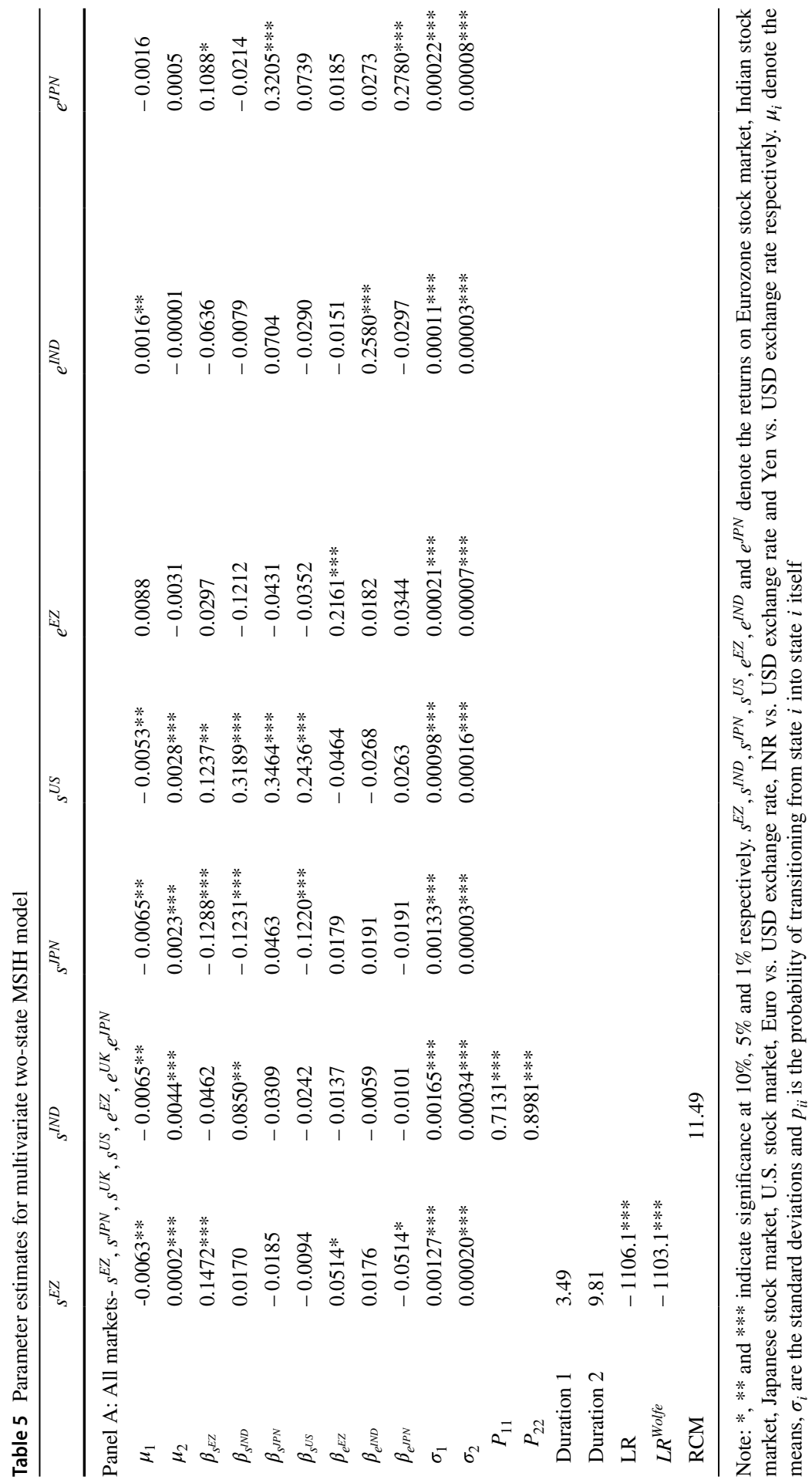


for all the stock markets. This has crucial implications for the international portfolio diversification across equity markets which would never be beneficial in practice due to the high degree of co-movement during periods of turmoil. The tranquil regime is found to be more persistent and less volatile relative to the 'turbulent' or 'turmoil' regime. This means that the data generating process exhibits 'normal' or 'tranquil' time periods disrupted by transitory outbreaks of 'turbulent' or 'crisis' time periods.

The autoregressive parameters are not found to be state-dependent. However, a closer look at the estimates suggests that S\&P 500 index positively impacts all the stock markets. Therefore, the importance of U.S. stock markets cannot be emphasized enough in the context of global stock market trade. The RCM statistic is much below 50 and the model fit is good.

Table 6 Panel B presents the estimates of contemporaneous correlation among the asset return pairs. We find that there exists a high degree of correlation among the stock markets especially during the periods of turmoil or crisis. Moreover, the correlations across the stock markets seem to spike during the periods of turmoil which suggests a strong possibility of 'contagion'. However, the currency market correlations tend to be lower during time periods of turmoil and higher during phases of tranquillity. This suggests that while portfolio diversification across international stocks may not be an effective strategy, that across the currencies may be beneficial. Another avenue is diversification across stocks and currencies since correlations across these tend to be low or negative during the turbulent phase.

Figure 2 plots the smoothed probabilities of being in a turbulent regime. Clearly, the tranquil regime is interrupted by occasional turbulence in the financial markets. The persistence of the tranquil regime is higher with $p_{22}$ is 0.89 as compared to the turmoil regime with $p_{11}$ is 0.71 . The average duration ${ }^{20}$ of the two regimes is 10 weeks and 4 weeks respectively.

The figure also highlights turbulent periods for the markets and coincide with major global events ${ }^{21}$ viz. the Brazilian devaluation of 1999 followed by the dotcom bubble burst of 2000-01 and the terrorist attacks of 9/11 in the United States in 2001. Subsequently, the South American crisis of 2002 and the Iraq war in 2003. After a prolonged period of stability, the sub-prime and global financial meltdown of 2007-2009, the Eurozone debt crisis in 2010-2013 and the Eurozone deflation in 2015. These are followed by the Taper Tantrum of 2015, Greek government debt crisis of 2016, Brexit in 2016, U.S. Federal government shutdown in 2018, U.S.China trade war in 2019 and the ongoing COVID-19 pandemic. The events ${ }^{22}$ corresponding to each of the episodes identified by the MS-VAR model are presented in Table 7.

\footnotetext{
20 The average duration of being in regime $i$ is given by $\frac{1}{1-p_{i i}}$.

21 The probability cut-off for the events is 0.98 .

22 As given in Chan et al. (2011), we conduct a robustness test for our results by partitioning the full sample into two sub-sample periods: July, 1999 to February, 2010 and March, 2010 to October, 2020. We identify two regimes (tranquil and turmoil regimes) for both the sub-periods. The results pertaining to the events highlighted in the paper are also corroborated. We are grateful to an anonymous Reviewer for suggesting this.
} 
Therefore, from an analysis of the conditional joint distribution of the asset returns, we find two states-tranquil regime characterized by relatively lower volatility and higher returns and the turbulent regime depicted by higher volatility and lower returns. An analysis of the contemporaneous correlations among asset market pairs indicates possibility of diversification across asset classes and within currencies but not stock markets.

To sum up, we identify two states utilizing the MS-VAR model for the conditional joint distribution of the asset returns. The states are tranquil and turmoil periods characterized by low and high volatility respectively. Similar evidence has been obtained by Kanas (2005), Chan et al. (2011), Guo et al. (2011), Chevallier (2012) and Chikli and Nguyen (2014). In particular, both Kanas (2005) and Chkili and Nguyen (2014) find two regimes using the MS-VAR model for stock and currency markets. In particular, the impact of COVID-19 on the international markets has been documented in other recent studies such as Mazur et al. (2021), Narayan (2020) and Narayan et al. (2020).

\section{Conclusions}

This paper examines the regime switching behaviour of international financial markets viz. Eurozone, India, Japanese and U.S. currency and equity markets. We seek to characterize the market-specific, asset-class specific and common regime shifts in international stock and currency markets. Further, we aim to study regime-dependent conditional correlations across these markets. We estimate state-dependent models for the financial markets in a univariate MS-AR as well as multivariate MS-VAR.

Our univariate results identify two-states for all the markets which we inferred to be the 'bear' regime (or state one) or the manner in which asset markets behave during economic contractions and the 'bull' regime (or state two) or the behaviour of asset markets during an economic expansions. The volatility is lower for all the asset markets during the bullish regime as compared to the bearish regime. The bull regime is also found to be more persistent for the markets with the exception of the Euro/USD and INR/USD rates. In the bullish phase, mean returns of all the markets are higher (barring the Euro/USD and INR/USD) than in the bearish regime. However, since the regime switches are random, we cannot predict these and, therefore, leverage this information for portfolio diversification. Moreover, we observe a high degree of overlap among the regimes and identify four distinct periods of economic contractions or bear regime from the analysis viz. the dot-com bubble burst of 2001-02, the global financial meltdown of 2008-09, the Eurozone debt crisis of 2011-12 and the ongoing pandemic COVID-19.

Subsequently, we utilize the multivariate MS-VAR models with MSIH specification to analyse the regimes across asset classes. We find two states-tranquil regime characterized by relatively lower volatility and higher equity returns and the turbulent regime depicted by higher volatility and lower equity returns in the model encompassing stock as well as currency markets. The 'tranquil' regime is found to be more persistent and less volatile relative to the 'turbulent' regime. However, in the case of currency markets the Euro/USD and INR/USD rates displays negative 
Table 6 Multivariate MSIH correlation coefficient estimates

\begin{tabular}{|c|c|c|c|c|c|c|}
\hline$s^{U S}$ & $s^{I N D}$ & $s^{J P N}$ & $s^{E Z}$ & $e^{E Z}$ & $e^{I N D}$ & $e^{J P N}$ \\
\hline
\end{tabular}

Panel B: All markets: $s^{E Z}, s^{J P N}, s^{U K}, s^{U S}, e^{E Z}, e^{U K}, e^{J P N}$

Correlations (turbulence regime)

$\begin{array}{llllllll}s^{U S} & 1.000 & & & & & \\ s^{I N D} & 0.499 * * * & 1.000 & & & & \\ s^{J P N} & 0.654 * * * & 0.541 * * * & 1.000 & & & \\ s^{E Z} & 0.830 * * * & 0.513 * * * & 0.685 * * * & 1.000 & & \\ e^{E Z} & -0.207 * * * & -0.251 * * * & -0.143 * * & -0.009 * * * & 1.000 & \\ e^{U K} & -0.379 * * * & -0.491 * * * & -0.352 * * * & -0.346 * * * & 0.297 * * * & 1.000 & \\ e^{J P N} & 0.198 * * * & 0.214 * * * & 0.371 * * * & 0.279 & 0.158 * * * & -0.121 * & 1.000\end{array}$

Correlations (Tranquil Regime)

\begin{tabular}{|c|c|c|c|c|c|c|c|}
\hline$s^{U S}$ & 1.000 & & & & & & \\
\hline$s^{I N D}$ & $0.400 * * *$ & 1.000 & & & & & \\
\hline$s^{J P N}$ & $0.615^{* * * *}$ & $0.393 * * *$ & 1.000 & & & & \\
\hline$s^{E Z}$ & $0.792 * * *$ & $0.442 * * *$ & $0.638 * * *$ & 1.000 & & & \\
\hline$e^{E Z}$ & $-0.115^{* * * *}$ & $-0.126^{* * * *}$ & 0.004 & $0.094 * * *$ & 1.000 & & \\
\hline$e^{U K}$ & $-0.280 * * *$ & $-0.426^{* * * *}$ & $-0.182 * * *$ & $-0.254 * * *$ & $0.285^{* * *}$ & 1.000 & \\
\hline$e^{J P N}$ & $0.216^{* * * *}$ & $0.102 * * *$ & $0.425 * * *$ & 0.318 & $0.333 * * *$ & $0.067 * * *$ & 1.000 \\
\hline
\end{tabular}

$*, * *$ and $* * *$ indicate significance at $10 \%, 5 \%$ and $1 \%$ respectively. $s^{E Z}, s^{I N D}, s^{J P N}, s^{U S}, e^{E Z}, e^{I N D}$ and $e^{J P N}$ denote the returns on Eurozone stock market, Indian stock market, Japanese stock market, U.S. stock market, Euro vs. USD exchange rate, INR vs. USD exchange rate and Yen vs. USD exchange rate respectively

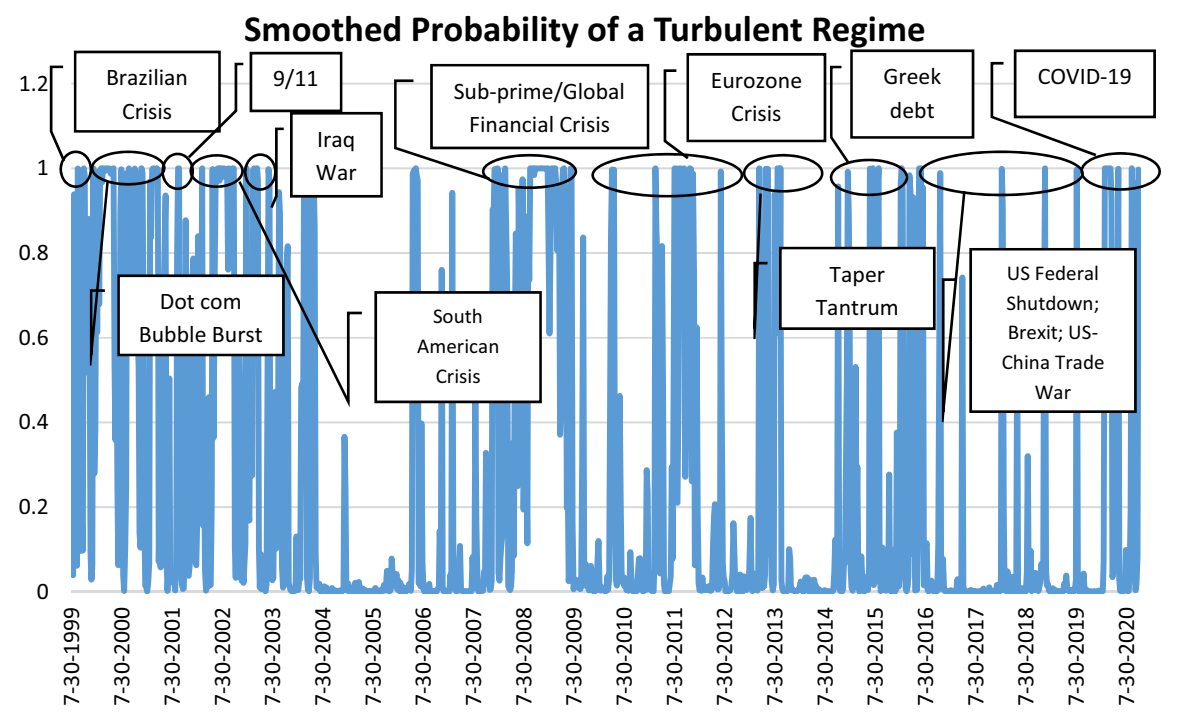

Fig. 2 Smoothed Probability of the Turbulent Regime for Multivariate MSIH Models 
Table 7 Events identified as turbulent regime across asset classes

\begin{tabular}{|c|c|}
\hline Dates & Event/s \\
\hline $\begin{array}{l}17 / 9 / 1999 ; 29 / 10 / 1999 \text { to } 5 / 11 / 1999 ; 7 / 1 / 2000 ; \\
11 / 2 / 2000 ; 25 / 2 / 2000 \text { to } 3 / 3 / 2000\end{array}$ & $\begin{array}{l}\text { Brazilian crisis continues; Corruption charges and } \\
\text { terrorism rock Russia; Argentine crisis worsens }\end{array}$ \\
\hline $17 / 3 / 2000$ to $2 / 6 / 2000$ & $\begin{array}{l}\text { Interest Hikes by ECB; Rising oil prices; Dotcom } \\
\text { bubble burst begins; Japan enters a recession }\end{array}$ \\
\hline $\begin{array}{l}28 / 7 / 2000 ; 8 / 9 / 2000 ; 22 / 9 / 2000 ; 3 / 11 / 2000 \text { to } \\
10 / 11 / 2000 ; 22 / 12 / 2000 \text { to } 29 / 12 / 2000\end{array}$ & $\begin{array}{l}\text { Dotcom bubble burst continues; International } \\
\text { markets especially IT stocks crash; Fed is forced } \\
\text { to cut interest rates }\end{array}$ \\
\hline $9 / 3 / 2001$ to $20 / 4 / 2001$ & U.S. slides into a recession \\
\hline $14 / 9 / 2001$ to $21 / 9 / 2001$ & $\begin{array}{l}\text { Uncertainty after } 9 / 11 \text { Terrorist Attacks; Markets } \\
\text { plummet as investors seek safe haven following } \\
\text { terrorist attacks in the U.S.; Attacks on Afghani- } \\
\text { stan begin; Number of Jobless increase sharply in } \\
\text { U.S.; Trough in the business cycle }\end{array}$ \\
\hline 08/03/2002 & $\begin{array}{l}\text { War in Afghanistan escalates Fed chief; Although } \\
\text { Alan Greenspan declares recession in U.S. over }\end{array}$ \\
\hline $\begin{array}{l}24 / 5 / 2002 ; 21 / 6 / 2002 \text { to } 5 / 7 / 2002 ; 19 / 76 / 9 / 2002 \text { to } \\
6 / 9 / 2002 ; 20 / 9 / 2002 ; 4 / 10 / 2002 \text { to } 25 / 10 / 2002 \text {; } \\
24 / 1 / 2003\end{array}$ & $\begin{array}{l}\text { South American Crisis; Uruguay Banking Crisis; } \\
\text { Reversal in Fed's interest rate policy }\end{array}$ \\
\hline $14 / 3 / 2003$ to $28 / 3 / 2003 ; 11 / 4 / 2003 ; 4 / 7 / 2003$ & Iraq War of 2000 begins \\
\hline $19 / 3 / 2004$ & $\begin{array}{l}\text { Blasts in Iraq and Bombings in Spain; Fighting } \\
\text { continues in Sudan; Situation deteriorates in } \\
\text { Afghanistan, Indonesia, Israel, Pakistan, Syria and } \\
\text { Venezuala }\end{array}$ \\
\hline $14 / 5 / 2004$ to $28 / 5 / 2004$ & $\begin{array}{l}\text { Political upset in India causes massive fall in } \\
\text { markets }\end{array}$ \\
\hline $19 / 5 / 2006$ to $26 / 5 / 2006 ; 9 / 6 / 2006$ to $23 / 6 / 2006$ & $\begin{array}{l}\text { Fed hikes interest rates; Capital Outflows from } \\
\text { emerging markets }\end{array}$ \\
\hline 4/1/2008; 25/1/2008; 7/3/2008; 21/3/2008 & Housing Bubble Burst in the U.S \\
\hline $19 / 9 / 2008$ to $23 / 1 / 2009$ & $\begin{array}{l}\text { World Bank forecasts indicate growth slowdown } \\
\text { in the U.S.; Countrywide Financial is to be pur- } \\
\text { chased by Bank of America for } \$ 4 \text { billion; Ambac } \\
\text { Financial Group's rating is downgraded by Fitch } \\
\text { Ratings and Standard and Poor's to negative on } \\
\text { the Credit Watch; US home sales witness largest } \\
\text { single-year drop in a quarter of a century }\end{array}$ \\
\hline $20 / 2 / 2009$ to $20 / 3 / 2009$ & $\begin{array}{l}\text { Bear Stearns is purchased for } \$ 2 \text { a share by JPMor- } \\
\text { gan Chase; Problems caused by overexposure to } \\
\text { the subprime mortgage crisis; Dow Jones Indus- } \\
\text { trial Average at the lowest level since October } \\
\text { 2006, falling more than } 20 \% \text { from its peak just five } \\
\text { months prior }\end{array}$ \\
\hline $15 / 5 / 2009$ to $22 / 5 / 2009 ; 10 / 7 / 2009$ to $17 / 7 / 2009$ & $\begin{array}{l}\text { U.S. Labour Department reports unemployment } \\
\text { increases from } 9.4 \% \text { in May to } 9.5 \% \text { in June } 2009\end{array}$ \\
\hline $7 / 5 / 2010 ; 21 / 5 / 2010$ & $\begin{array}{l}\text { Greece announces public debt issues; Eurozone } \\
\text { finance ministers grant loans worth } € 110 \text { billion to } \\
\text { bail out Greece for the first time; IMF and EU set } \\
\text { up financial stability fund worth } € 750 \text { billion }\end{array}$ \\
\hline $18 / 03 / 2011$ & $\begin{array}{l}\text { Japan Earthquake and Tsunami; Chancellor revises } \\
\text { down UK growth forecasts }\end{array}$ \\
\hline
\end{tabular}


Table 7 (continued)

\begin{tabular}{ll}
\hline Dates & Event/s \\
\hline $5 / 8 / 2011$ to $12 / 8 / 2011 ; 9 / 9 / 2011$ to $30 / 9 / 2011 ;$ & European Central Bank announces that it will buy \\
$14 / 10 / 2011 ; 4 / 11 / 2011$ to $2 / 12 / 2011 ; 16 / 12 / 2011$ & Italian and Spanish bonds; ECB to grant unlimited \\
& dollar loans for three months as EU institutions \\
& struggle to access US dollar; Bank of England \\
& injects £75 billion into the UK economy; Euro- \\
& zone approves $€ 8$ billion worth of bailout loans \\
& for Greece; Eurozone leaders convene in Brussels \\
& again with the intention of building a stronger \\
& Economic Union
\end{tabular}

$6 / 7 / 2012$

$12 / 04 / 2013$

$31 / 5 / 2013$ to $14 / 6 / 2013$

$23 / 8 / 2013$ to $30 / 8 / 2013$

$13 / 9 / 2013$

$16 / 01 / 2015$

26/6/2015 to $3 / 7 / 2015$

$17 / 7 / 2015$

$28 / 8 / 2015$

$5 / 2 / 2016$ to $19 / 2 / 2016$

$8 / 4 / 2016$ to $15 / 4 / 2016$

$6 / 5 / 2016$

$17 / 6 / 2016$ to $1 / 7 / 2016$

$15 / 7 / 2016$

$18 / 11 / 2016$

9/2/2018 to $16 / 2 / 2018$

$21 / 12 / 2018$

$9 / 8 / 2019$

\section{LIBOR Scandal in Europe}

US economy stalls as hiring in the U.S. slows down; Bombing at the Boston Marathon; Unemployment in Europe hits record high of $12 \%$

'Taper Tantrum' triggered by Bernanke

INR hits record low against USD; NASDAQ shut down for hours due to a computer glitch

\section{Syrian Civil War}

Elections in Greece and increasing tension hinting at Greece's exit from Eurozone; Eurozone deflation

Greece to hold referendum on bailout deal to creditors; Perpetuation of the Greek government-debt crisis

Chinese market collapse; Microsoft announces further job cuts; NYSE stops trade due to technical glitch; Puerto-Rican crisis

Stock markets crash due to fears regarding the Chinese economy as People's Bank of China cuts interest rates

Zika Virus Outbreak continues; Obama plans to tax crude oil

Syrian Civil War and Iraqi Civil War; Panama Paper Leaks; European Migrant Crisis

European Migrant Crisis continues; ongoing Syrian Civil War and Iraqi Civil War

UK Referendum to decide whether to leave E.U

Escalation in Iraqi Civil War, Jammu and Kashmir, Syria and South Sudanese Civil War; Theresa May Becomes PM of U.K

Donald Trump's election as President is responded with protests

International markets slide expecting higher inflation in the U.S. and Brexit negotiations takes centre stage along with U.S. Federal Government Shutdown; US China Trade War begins

Another partial U.S. Federal Government Shutdown China-U.S. trade war intensifies 
Table 7 (continued)

\begin{tabular}{ll}
\hline Dates & Event/s \\
\hline $28 / 2 / 2020$ to 17/4/2020 & $\begin{array}{l}\text { COVID-19 spreads outside of China and causes the } \\
\text { international markets to tank and leads several } \\
\text { economies to lockdown }\end{array}$ \\
COVID-19 worsens in Brazil as it records the \\
second-highest cases in the world \\
COVID-19 situation worsens in India and \$300 bil- \\
lion stimulus bill is blocked in the U.S. senate \\
COVID-19 cases suddenly spike again in U.S. and \\
India
\end{tabular}

Source: Authors' own compilation

weekly returns in the tranquil phases. The exchange rates Euro and INR depreciate during turbulent phases which are associated with higher volatility. On the contrary, Yen being a safe haven currency appreciates during high volatility turbulent periods.

Contemporaneous correlations among asset market pairs suggest that portfolio diversification possibilities exist across stock and currency markets or currency markets alone since correlations amongst these assets tend to be lower during turbulent phases (similar to Dua and Tuteja 2016). This has crucial implications for the portfolio diversification across international stock markets which would never be beneficial in practice due to the high degree of co-movement during periods of turmoil. The turbulent periods highlighted in the analysis correspond to major geopolitical and economic events such as the Brazilian crisis, dot-com bubble burst, terrorist attack of 9/11, South American crisis of 2002, Iraq war, the sub-prime and global financial crisis, the Eurozone debt crisis and Eurozone deflation in 2015, followed by the Taper Tantrum of 2015, Greek government debt crisis of 2016, Brexit in 2016, U.S. Federal government shutdown in 2018, U.S.-China trade war in 2019 and the ongoing COVID-19 pandemic.

Acknowledgements The authors are grateful to the Editors and the two anonymous Referees for their comments and suggestions that helped improve the paper.

\section{References}

Andreou, E., M. Matsi, and A. Savvides. 2013. Stock and foreign exchange market linkages in emerging economies. Journal of International Financial Markets, Institutions and Money 27: 248-268.

Ang, A., and G. Bekaert. 2002. International asset allocation with regime shifts. Review of Financial Studies 15: 1137-1187.

Bae, G.I., W.C. Kim, and J.M. Mulvey. 2014. Dynamic asset allocation for varied financial markets under regime switching framework. European Journal of Operational Research 234: 450-458.

Boschi, M. 2005. International financial contagion: Evidence from the Argentine crisis of 2001-2002. Applied Financial Economics 15: 153-163.

Chan, K.F., S. Treepongkaruna, R. Brooks, and S. Gray. 2011. Asset market linkages: Evidence from financial, commodity and real estate assets. Journal of Banking and Finance 35: 1415-1426. 
Chang, K.-L. 2009. Do macroeconomic variables have regime-dependent effects on stock return dynamics? Evidence from the Markov Regime Switching Model. Economic Modelling 26: 1283-1299.

Chesnay, F., and E. Jondeau. 2001. Does correlation between stock returns really increase during turbulent periods? Economic Notes 30 (1): 53-80.

Chevallier, J. 2012. Global imbalances, cross market linkages, and the financial crisis: A multivariate Markov-switching analysis. Economic Modelling 29: 943-973.

Chkili, W. 2017. Is gold a hedge or safe haven for Islamic stock market movements? A Markov switching approach. Journal of Multinational Financial Management 42: 152-163.

Chkili, W., and D.K. Nguyen. 2014. Exchange rate movements and stock market returns in a regimeswitching environment: Evidence for BRICS countries. Research in International Business and Finance 31: 46-56.

Chkili, W., A. Chaker, O. Masood, and J. Fry. 2011. Stock market volatility and exchange rates in emerging countries: A Markov-state switching approach. Emerging Markets Review 12: 272-292.

Davies, R.B. 1977. Hypothesis testing when a nuisance parameter is present only under the alternative. Biometrika 64: 247-254.

Dempster, A., N. Laird, and D. Rubin. 1977. Maximum likelihood from incomplete data via the EM algorithm. Journal of the Royal Statistical Society Series B 39: 1-38.

Diamandis, P.F., and A.A. Drakos. 2011. Financial liberalization, exchange rates and stock prices: Exogenous shocks in four Latin America countries. Journal of Policy Modeling 33: 381-394.

Dimitriou, D., and D. Kenourgios. 2013. Financial crises and dynamic linkages among international currencies. Journal of International Financial Markets, Institutions and Money 26: 319-332.

Dua, P., and D. Tuteja. 2016. Financial crises and dynamic linkages across international stock and currency markets. Economic Modelling 59: 249-261.

Dueker, M., and C.J. Neely. 2007. Can Markov switching models predict excess foreign exchange returns? Journal of Banking and Finance 31 (2): 279-296.

Dungey, M., and V.L. Martin. 2007. Unravelling Financial Market Linkages during Crises. Journal of Applied Econometrics 22: 89-119.

Elliott, G., T.J. Rothenberg, and J.H. Stock. 1996. Efficient tests for an autoregressive unit root. Econometrica 64: 813-836.

Flavin, T.J., E. Panopoulou, and D. Unalmis. 2008. On the Stability of Domestic Financial Market Linkages in the Presence of Time-varying Volatility. Emerging Markets Review 9: 280-301.

Garcia, R. 1993. Asymptotic null distribution of the likelihood ratio test in Markov switching models, Université de Montréal, Working Paper.

Goodwin, T.H. 1993. Business-cycle analysis with a Markov-switching model. Journal of Business \& Economic Statistics 11: 331-339.

Granger, C., B. Huang, and C. Yang. 2000. Bivariate causality between stock prices and exchange rates in Asian countries. The Quarterly Review of Economics and Finance 40: 337-354.

Guidolin, M. 2011. Markov switching models in empirical finance, Missing Data Methods: Time-series methods and applications. Advances in Econometrics 27B: 1-86.

Guidolin, M., and A. Timmermann. 2006. An econometric model of nonlinear dynamics in the joint distribution of stock and bond returns. Journal of Applied Econometrics 21: 1-22.

Guidolin, M., and A. Timmermann. 2007. Asset allocation under multivariate regime switching. Journal of Economic Dynamics and Control 31: 3503-3544.

Guo, F., C.R. Chen, and Y.S. Huang. 2011. Markets contagion during financial crisis: A regime-switching approach. International Review of Economics and Finance 20: 95-109.

Hamilton, J.D. 1989. A new approach to the economic analysis of nonstationary time series and the business cycle. Econometrica 57: 357-384.

Hamilton, J.D. 1990. Analysis of time series subject to changes in regime. Journal of Econometrics 45: $39-70$.

Hamilton, J.D. 1994. Time series analysis. Princeton, NJ: Princeton University Press.

Hansen, B.E. 1992. The likelihood ratio test under non-standard conditions: Testing the Markov switching model of GNP. Journal of Applied Econometerics 7: S61-S82.

Hatemi-J, A., and E. Roca. 2005. Exchange rates and stock prices interaction during good and bad times: Evidence from the ASEAN4 countries. Applied Financial Economics 15: 539-546.

Kallberg, J.G., C.H. Liu, and P. Pasquariello. 2005. An examination of the Asian Crisis: Regime shifts in currency and equity markets. The Journal of Business 78: 169-211.

Kanas, A. 2005. Regime linkages between the Mexican currency market and emerging equity markets. Economic Modelling 22: 109-125. 
Krolzig, H.-M. 1997. Markov-switching vector autoregressions: Modelling, statistical inference, and application to business cycle analysis. In Lecture notes in economics and mathematical systems, 454th ed. Berlin: Springer-Verlag.

Lee, J., and M.C. Strazicich. 2003. Minimum Lagrange multiplier unit root test with structural breaks. The Review of Economics and Statistics 85: 1082-1089.

Leroux, B.G. 1992. Consistent estimation of a mixing distribution. The Annals of Statistics 20: 1350-1360.

Lin, C.-H. 2012. The comovement between exchange rates and stock prices in the Asian emerging markets. International Review of Economics and Finance 22: 161-172.

Mazur, M., M. Dang, and M. Vega. 2021. COVID-19 and the March 2020 stock market crash. Evidence from S\&P1500. Finance Research Letters 38:101690

McLachlan, G.J., and D. Peel. 2000. Finite mixture models. Wiley Series in Probability and Statistics. New York: Wiley.

Narayan, P.K. 2020. Has COVID-19 changed exchange rate resistance to shocks? Asian Economics Letters 1 (1): 17389.

Narayan, P.K., N. Devpura, and H. Wang. 2020. Japanese currency and stock market-What happened during the COVID-19 pandemic? Economic Analysis and Policy 68: 191-198.

Pan, M.S., R.C.W. Folk, and Y.A. Liu. 2007. Dynamic linkages between exchange rates and stock prices: Evidence from East Asian Markets. International Review of Economics and Finance 16: 503-520.

Pavlova, A., and R. Rigobon. 2008. The role of portfolio constraints in the international propagation of shocks. Review of Economic Studies 75: 1215-1256.

Peel, D., W.J. Whiten, and G.J. McLachlan,. 2001. Fitting mixtures of Kent distributions to aid in joint set identification. Journal of the American Statistical Society 96: 56-63.

Phylaktis, K., and F. Ravazzolo. 2005. Stock prices and exchange rate dynamics. Journal of International Money and Finance 24: 1031-1053.

Qiao, Z., Y. Li, and W.K. Wong. 2011. Regime-dependent relationships among the stock markets of the US, Australia and New Zealand: A Markov-switching VAR approach. Applied Financial Economics 21 (24): 1831-1841.

Ranaldo, A., and P. Söderlind. 2010. Safe haven currencies. Review of finance 14 (3): 385-407.

Roubaud, D., and M. Arouri. 2018. Oil prices, exchange rates and stock markets under uncertainty and regime-switching. Finance Research Letters 27: 28-33.

Sclove, S.L. 1983. Time-series segmentation: A model and a method. Information Sciences 29: 7-25.

Tai, C.-S. 2007. Market integration and contagion: Evidence from Asian emerging stock and foreign exchange markets. Emerging Markets Review 8: 264-283.

Tillmann, P. 2004. Disparate information and the probability of currency crises: Empirical evidence. Economics Letters 84 (1): 61-68.

Tsagkanos, A., and C. Siriopoulos. 2013. A long-run relationship between stock price Index and exchange rate: A structural nonparametric cointegrating regression approach. Journal of International Financial Markets, Institutions and Money 25: 106-118.

Tsay, R.S. 1986. Nonlinearity tests for time series. Biometrika 73: 461-466.

Turner, C.M., R. Startz, and C.R. Nelson. 1989. A markov model of heteroskedasticity, risk, and learning in the stock market. Journal of Financial Economics 25 (1): 3-22.

Walid, C., A. Chaker, O. Masood, and J. Fry. 2011. Stock market volatility and exchange rates in emerging countries: A Markov-state switching approach. Emerging Markets Review 12: 272-292.

Wang, P., and M.L. Puterman. 1999. Markov Poisson regression models for discrete time series, Part 1: Methodology. Journal of Applied Statistics 26: 855-869.

Wang, P., and M. Theobald. 2008. Regime-switching volatility of six East Asian emerging markets. Research in International Business and Finance 22: 267-283.

Wolfe, J.H. 1971. A Monte Carlo study of the sampling distribution of the likelihood ratio for mixtures of multinormal distributions, Technical Bulletin STB-72-2 (Naval Personnel and Training Research Laboratory, San Diego, CA).

Zhao, H. 2010. Dynamic relationship between exchange rate and stock price: Evidence from China. Research in International Business and Finance 24: 103-114.

Zolfaghari, M., and B. Sahabi. 2017. Impact of foreign exchange rate on oil companies risk in stock market: A Markov-switching approach. Journal of Computational and Applied Mathematics 317: 274-289.

Publisher's Note Springer Nature remains neutral with regard to jurisdictional claims in published maps and institutional affiliations. 